\title{
Vorwort zur zwölften Auflage.
}

Als ich im Sommer des vorigen Jahres mit den Vorbereitungen für diese zwölfte Auflage beschäftigt war, brach der Krieg aus und teilte mir der Herr Verleger auf meine Anfrage mit, daB die Herausgabe bis nach Friedensschlu $B$ aufgeschoben werden sollte. Es ist mir eine große Genugtuung, daB trotz des Krieges doch die Erscheinung der neuen Auflage notwendig geworden ist.

Den unfreiwilligen Aufschub hahe ich benutzt, um noch einige Änderungen im Manuskript anzubringen.

An der vorhergehenden Auflage sind nun folgende Änderungen angebracht: 1. Weiteres wurde mitgeteilt über WeRNERs Untersuchungen betreffend optischer Isomerie, durch andere Atome als C-Atome verursacht. 2. Die Versuche Wirlands über die Oxydation der Aldehyde usw. wurden aufgenommen. 3. Das Härten der Öle wurde erwähnt. 4. Der Abschnitt über die Einwirkung von Oxalsäure auf Glycerin wurde ganz neu geschrieben. 5. Ein neuer Abschnitt wurde eingefügt über die Synthese von Monosen. 6. Der Abschnitt über die technische Darstellung der Cyanide wurde neu geschrieben. 7. Ein neuer Abschnitt wurde eingefügt über die Anwendung des ultravioletten Absorptionsspektrums zur Bestimmung der Struktur. 8. Der Abschnitt über Phtalylderivate wurde ganz umgearbeitet. 9. Eine kurze Übersicht über WiLlstätrens hervorragende Chlorophylluntersuchungen wurde eingereiht. 10. Der Abriß über Alkaloide wurde ganz umgearbeitet.

Bloemendaal, August 1915.

\section{A. F. Holleman.}

\section{Chronologie.}

1. Auflage: Oktober 1898; 2. Auflage: Oktober 1902; 3. Auflage: Februar 1904;

4. Auflage: August 1905; 5. Auflage: Oktober 1906; 6. Auflage: Januar 1908;

7. Auflage: Mai 1909; 8. Auflage: Mai 1910; 9. Auflage: Juni 1911;

10. (erhöhte) Auflage: August 1912; 11. Auflage: September 1913.

12. Auflage: August 1915. 
